\title{
1. Globalization and regional economies
}

Regional and local economies are systems within systems. Therefore, to have a better grip on regional and local economic development it is crucial to study and understand the wider environment within which these economies operate. In other words, it is necessary to see the forest before focusing on trees. Of course, national economies are important for regions, but there is a larger and as important world economy that has a significant influence on both national and regional economies. Hence, it is essential to start with an understanding of the changing world economy or, in a more trendy term, of globalization.

From the early 1990s, unprecedented changes in the world economy have been observed. These changes started a long time ago and gained speed in the 1980s, but since the 1990s the organization, composition, integration and interdependency of the world economy have gone through drastic changes. For a detailed historical account of globalization see Held et al. (1999), Langhorne (2001) and Dreher et al. (2008). This recent progress is qualitatively different from the earlier expansion of international trade, which is more than an increase in volume and frequency of trade. In this new development, trade and resource flows are more complex and often involve economic agents and structures performing at the micro level (Cook and Kirkpatrick, 1997). There is still considerable disagreement over the definition and interpretation of globalization, in the organization of economic and social activities at the global scale and whether we are in a globalized world or moving toward it (Dicken, 1994).

In its simple form, globalization refers to trade liberalization and increasing factor mobility across the world and is generally described as increasing internationalization of the financial systems and markets for goods and services. It is a dynamic and multidimensional process of economic integration, in which national and regional resources have become more and more internationally mobile while both national and regional economies became increasingly interdependent (OECD, 2010). In a general sense, it is defined as the molding of multiplicity of linkages and interconnections between various actors of the modern world system such as firms, states and people. As a result of this process decisions and 
activities in one part of the world can have significant impacts on other parts of the world (McGrew, 1992). Focusing on economic aspects of globalization Oman (1994) argues that globalization covers a wide range of economic and political issues on a global scale including evolution of the world trading system, the need for international policy integration and the role of national economic policymaking in the integration process.

Molle (2002) makes a distinction between globalization and regional economic integration (regionalization) and defines globalization as the increase in the size and frequency of economic transaction between various actors around the world driven by advancement in technology and changing policies toward liberalization of trade and capital movements. Similarly, Krieger-Boden and Soltwedel (2013) distinguish economic integration (EU in particular) from globalization and argue that even though both take place simultaneously, they have different characteristics in terms of their driving forces, associated transaction costs and effects. For Krieger-Boden and Soltwedel (2013) regional economic integration is limited to a specific geographic region and covers a number of states while globalization is open to all countries wishing to be involved. Regional integration has a certain time frame and is driven largely by institutional progress while the globalization process is indeterminate and driven by technological and institutional progress as well as innovations in industrial organizations and financial markets.

Dreher et al. (2008) define globalization as the process of creating networks of connections among actors at different parts of the world, facilitated by a range of flows including people, information and ideas, capital and goods. For them, globalization erodes national boundaries, integrates economies, cultures, technologies and governance and produces complex relations with mutual interdependence. Even though Dreher et al. (2008) provide this definition, they emphasize the importance of focusing on particular aspects or factors of globalization that could be very useful to adopt a multidimensional approach. They argue that this will prevent oversimplification of its complexities while permitting a flexible definition of contemporary globalization.

Rodrik (2013) provides an alternative narrative focusing on a different, in a sense, circular dynamic of the process. According to Rodrik this dynamic sustains a politically divided and economically less than fully globalized world, in which heterogeneity, institutional non-uniqueness and geography create a need for institutional diversity. Institutional diversity, in turn, hinders full globalization that reinforces heterogeneity and the role of geography. He argues that if the forces behind this dynamic are strong enough, operating by the rules of 'typical' globalization will only bring trouble around the world. 
In light of the above discussion, globalization can be defined as a multidimensional and complex process that has been initially driven by international trade, but particularly after World War II mainly steered by international organizations and multinational corporations that changes and, to a certain degree, shapes the economic, political and social structures as well as interactions among actors across the world with varying impacts on national, regional and local economies and people.

In addition to different definitions of globalization, there are different views on the interpretation of factors and events that shaped globalization and its economic, social and political impact on different countries and regions. There is an agreement that globalization is a reality and we are living in a globalized or globalizing world, but the debate on the benefits or the costs of globalization is not over. Depending on one's perspective globalization could mean increased dissemination of ideas and technologies and a positive transformation of the economic, political and cultural foundations of societies and thus should be promoted. From another perspective, it could mean a threat to national sovereignty and even culture by global actors and devastation of natural and human resources of a nation. To assess this conflict and manage it fruitfully require a clear understanding of how globalization works, what benefits and costs are associated with it and what policy choices are available for societies.

\section{MEASURING GLOBALIZATION: ARE WE THERE YET?}

There is agreement on the importance of measuring globalization and an awareness of the fact that without proper measurement it is not possible to evaluate benefits or the severity of the impacts of globalization on national and regional economies (Dreher et al., 2008).

In the literature, there are several approaches for measuring globalization and economic integration, but many of them are not well suited to measure the progress. Some of them try to quantify transaction costs by measuring distance or travel time and freight charges, however they fall short of covering all aspects of transaction costs (Krieger-Boden and Soltwedel, 2013). Some experts also use the cross country convergence studies to understand the globalization trend or lack of it. See, for example, two recent studies by Spence (2011) and Dadush and Shaw (2011) for a detailed account of convergence and globalization.

There are a number of indicators that are widely used to measure and monitor the globalization process. Two of the most commonly used indicators are international trade of goods and services and foreign direct 
investment (FDI). The logic behind using international trade and FDI is that their progress can demonstrate the increasing (decreasing) level of transactions among nations, which, in turn, can indicate the reduction (or escalation) of trade barriers and improvement of business climate in host nations. This is important because these attributes of economies are critical for attracting FDI and thus they are perceived as major signs of globalization. It should be noted that these catch-all indicators are sensitive to fluctuations (exchange rate, business cycles and economic and political crisis).

Krieger-Boden and Soltwedel (2013) provide a detailed overview of various approaches and indices to measure globalization and economic integration and compare their relative strengths and weaknesses. They report that some of these indices are explicitly designed to approximate the process of globalization such as the Economic Freedom of the World Index (EFW); KOF Globalization Index; T. Kearney Index; CSGR Warwick Globalization Index; Worldwide Governance Indicator (WGI); Indicator of Economic Freedom (IEF); Global Competitiveness Index (GCI); and OECD Globalization Indices. They argue that these are the most promising indices for the purpose, even though they have some shortcomings. Some of them include a mix of sub-indices that are partly associated with the driving forces of globalization and partly influenced by the outcomes of the integration process. As some of them covered relatively short periods, mainly more recent years, and focused more on general governance issues, their coverage and timely availability could be a concern for researchers. Most of these indicators are drawn from factual raw data.

In this book, the purpose is not an in depth analysis of globalization. Therefore, among these various indices the KOF Globalization Index is used to measure the integration process due to its convenience and availability for a long period of time as well as its proximity in integrating individual countries and major regions into the world economy. Further, the KOF Index is highly correlated with the international trade and FDI indicators. It should be noted, however, that the weights assigned to the sub-indices and their components seem arbitrary, which require some care in analysis.

Figure 1.1 shows the progress on international trade in the world for developing and developed countries in US dollars (in billions) at current prices and current exchange rates. It is clear that international trade started accelerating in the second half of the 1980s and significantly increased by the early 2000s. This is consistent with the globalization literature. A significant aspect of this trend is that around two thirds of international trade took place among developed countries. This information is also available for individual countries, trading blocks and regional unions from UNCTAD databases.

Figures 1.2 and 1.3 show the progress on the other popular indicator 


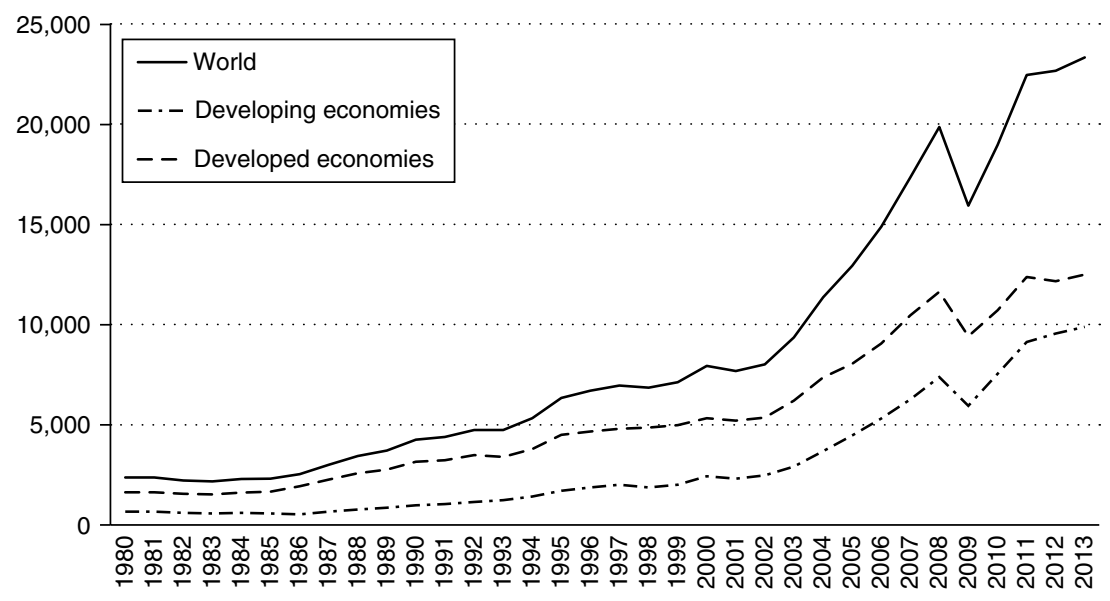

Source: UNCTAD, UNCTADstat.

Figure 1.1 International trade (exports of goods and services), 1980-2013

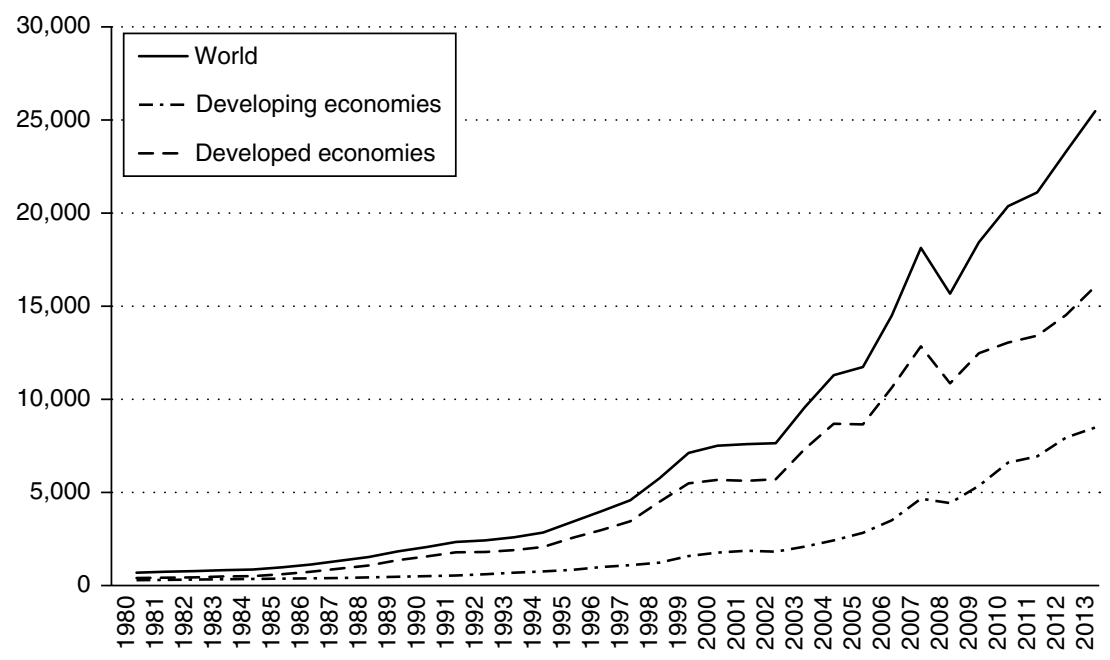

Source: UNCTAD, UNCTADstat.

Figure 1.2 Foreign direct investment stock (inward), 1980-2013 


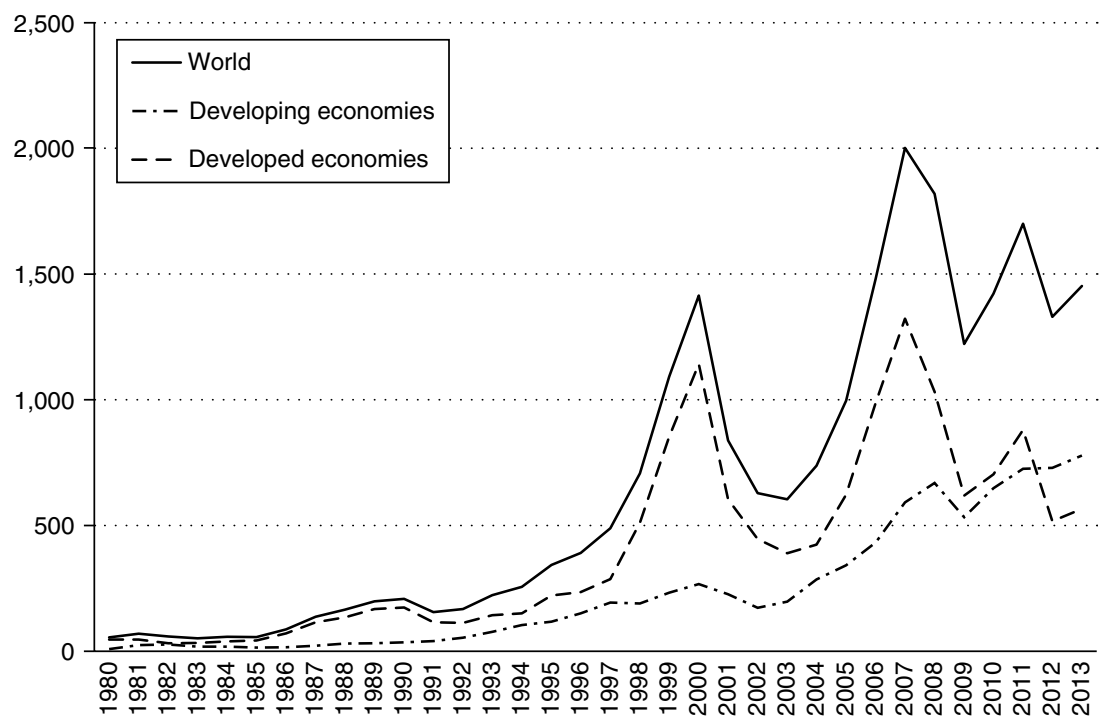

Source: UNCTAD, UNCTADstat.

Figure 1.3 Foreign direct investment flow (inward), 1980-2013

of globalization: foreign direct investment (FDI) in both stocks and flows from 1980 to 2013 in US dollars (in billions) at current prices and current exchange rates. The FDI stock trend is quite similar to that for international trade. It began accelerating in the late 1980s and gained considerable impetus in the late 1990s. Similarly, around 70 percent of FDI stocks have been in developed countries during that period. Meanwhile, FDI flow initially followed the same patterns as other indicators of globalization, but started fluctuating after 2000 particularly in developed countries. There was much less fluctuation in developing countries. This suggests that FDI flows are closely associated with major economic crises. The share of developing countries remained around one third of the total flow until the most recent global crisis when it increased to about 45 percent of total. It has since receded.

Both international trade and FDI indicators clearly show that the world economy is getting more and more interconnected. These indicators simplify our understanding of the multidimensional and complex process of globalization. Dreher (2006) and Dreher et al. (2008) adopt a more multidimensional and pluralistic approach to define and understand globalization and the type of factors and events that shaped it. They provide a comprehensive review of the literature on globalization and develop a 
framework for defining globalization and for analysing the relationships among economic, political and social variables. They also show how to apply their methodology to analyse the effects of globalization on issues such as tax policy, government spending, economic growth and inequality.

Globalization is, of course, not limited to just economic activities or trade of goods. Globalization has expanded the trade of both factor and non-factor services, but also made human, institutional and political relations as well as the natural environment more intertwined (Dreher et al., 2008). These social, political and environmental aspects of globalization have also had a profound impact on national, regional and local economies. New ideas take root in regions where local leadership and the business environment are supportive. This leads to rapid evolution and even leapfrogging opportunities for local and regional economies.

To investigate the multidimensional aspects of globalization the KOF Index of Globalization ${ }^{1}$ was introduced in 2002 (Dreher, published in 2006) and was updated and described in detail in Dreher et al. (2008). The overall index is an integrated measure of the economic, social and political dimensions of globalization. It defines globalization as the process of connections among actors at multi-continental distances through a variety of flows including people, information and ideas, capital and goods that interconnect and integrate economies, peoples, cultures, technologies and governance.

Figure 1.4 shows the globalization progress by major regions based on the KOF Index. Even though all follow the same trend, Europe is by far the most advanced in integration to the world followed by the Americas and Asia. An interesting observation is that until the early 1990s all major regions were closely bundled and moving upward together, but by 1990 Europe and Asia had a leap and started a steep ascending process in terms of integration. As seen in the figure Oceania is the least integrated region of the world. Given that Oceania comprises Pacific islands this observation is quite realistic and suggests that geography and distance are still important in economic, social and political integration.

The significance of 1990 in the globalization process could be partially attributed to the collapse of the Soviet Union and opening up of former Soviet countries. Around the same time, China launched broader trade reforms and introduced some concessions to the capital account that resulted in an acceleration of international trade and FDI. This could also be taken as another push for the globalization process. Major improvements in the Internet and social media all have had a strong impact on the progress of these two factors.

The economic globalization index is built around two dimensions. The first is about actual economic flows that are similar to international 


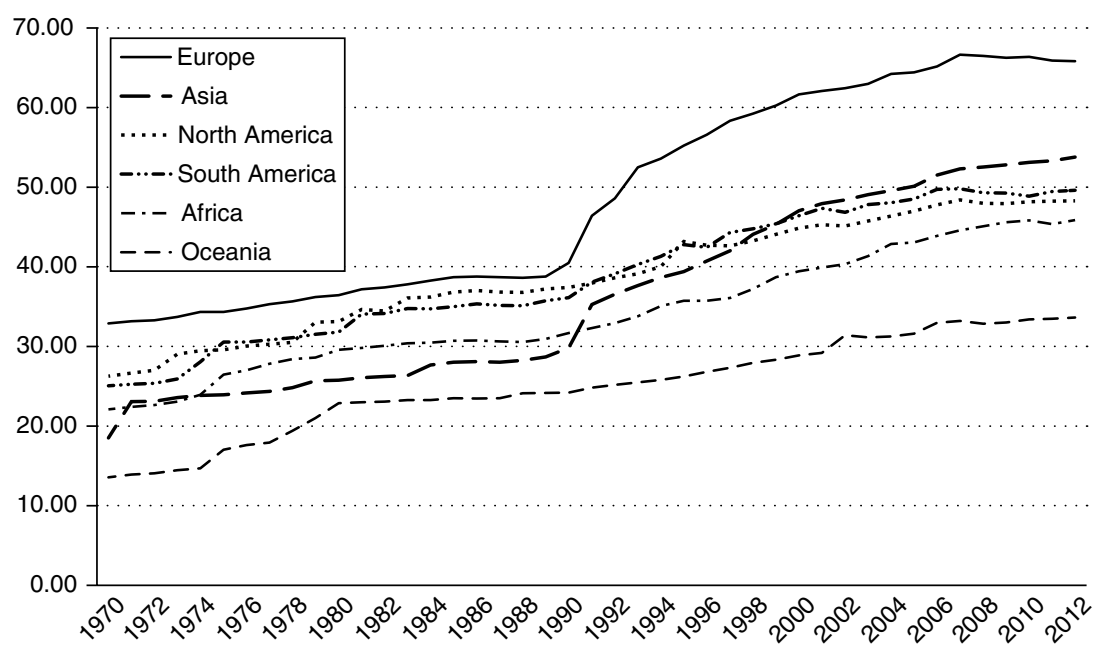

Source: KOF http://globalization.kof.ethz.ch/.

Figure 1.4 KOF Globalization Index (1970-2012)

trade and FDI indicators. The second dimension looks at the removal of restrictions to trade and capital. In a sense, economic globalization is described as flows of capital, goods and services along with accompanying information and perceptions. Figure 1.5 shows the economic globalization progress in major regions of the world. As seen in the figure, the trend is quite similar to the overall globalization process for all regions with a significant acceleration for Europe and Asia in the early 1990s. An interesting observation is that Africa seems more integrated to the world economy than the Americas and particularly around the last financial crisis the gap started widening.

The social globalization index is based on three categories: personal contacts, information flows and the cultural proximity. In this approach, social globalization represents the spread of ideas, information, images and people. This can have a profound impact on the lives of people by introducing new ideas and can also trigger significant changes in society that were not conceivable before. As seen in Figure 1.6 until the 1990s Europe and North America were quite close in terms of social integration, but since the early 1990s there was a steep acceleration in Europe while North America maintained its earlier pace. This could be attributed to the advancements in EU integration process and opening up of the Eastern European countries. Similarly, Asia had a jump in the early 1990s outperforming South America, Africa and Oceania. An interesting observation 


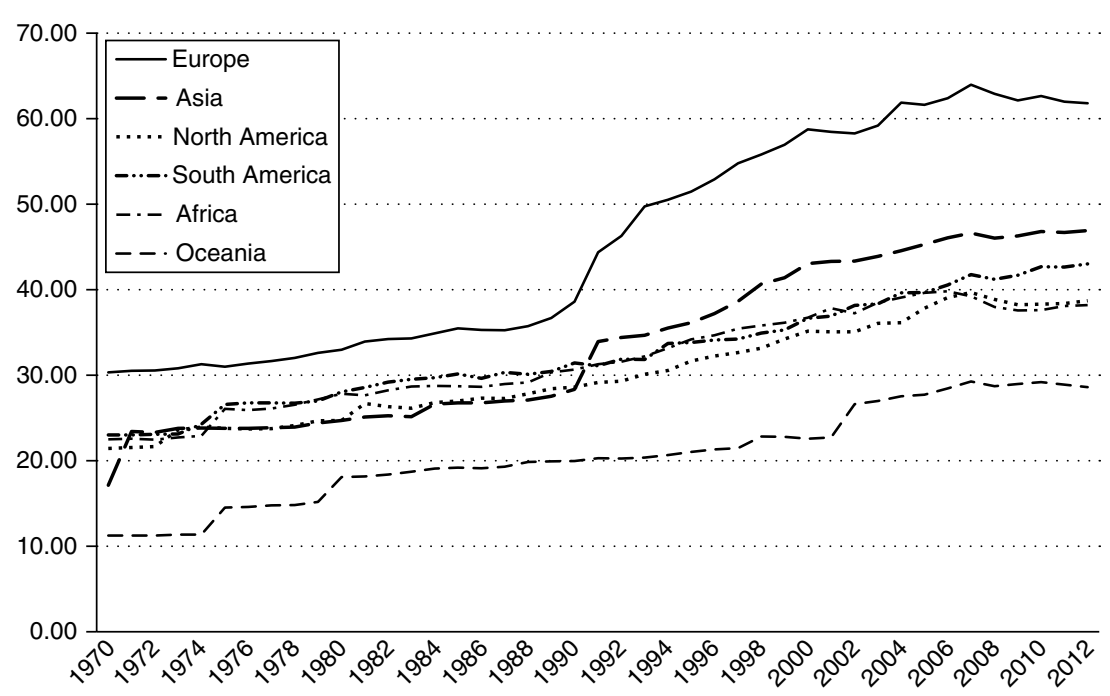

Source: KOF http://globalization.kof.ethz.ch/.

Figure 1.5 Economic globalization

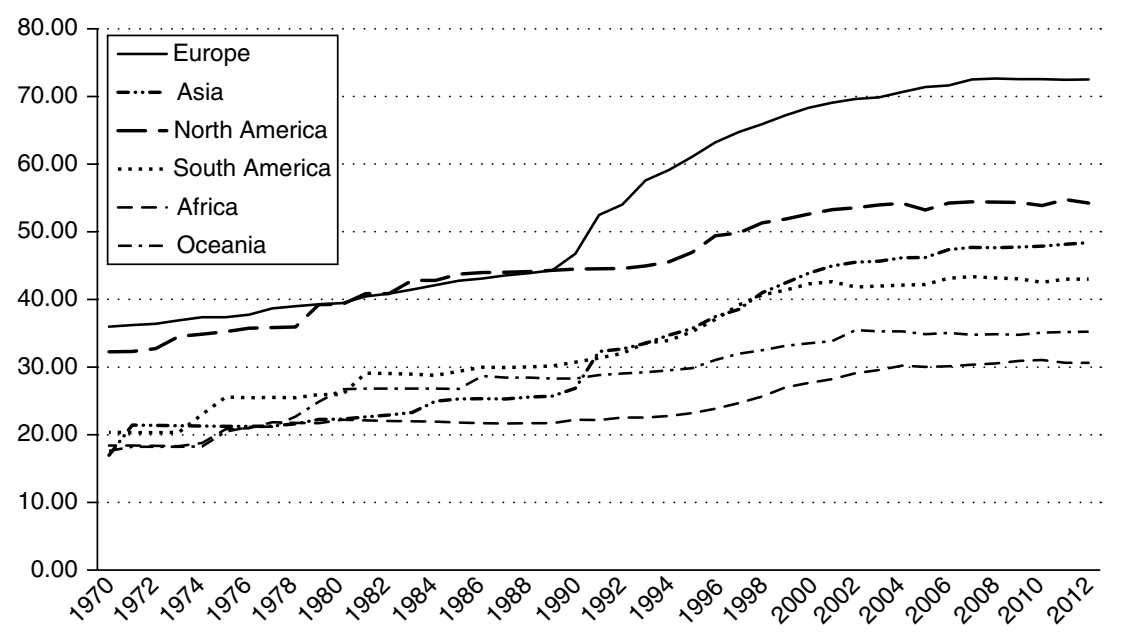

Source: KOF http://globalization.kof.ethz.ch/.

Figure 1.6 Social globalization 


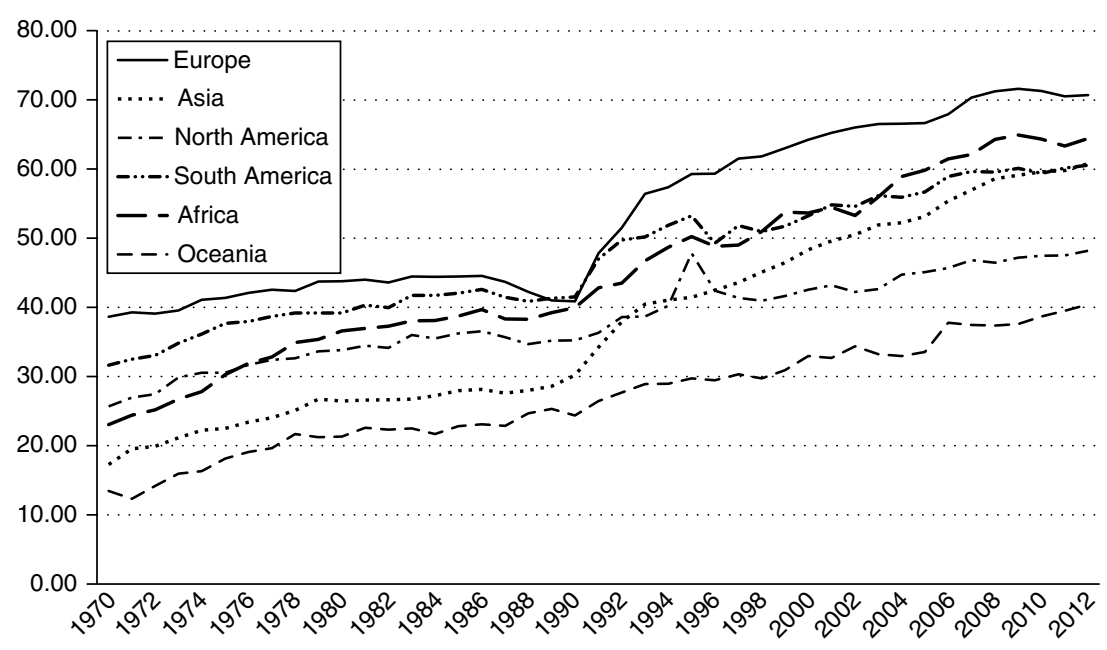

Source: KOF http://globalization.kof.ethz.ch/.

\section{Figure 1.7 Political globalization}

is that Oceania, the slowest globalizer in all other categories and still relatively slow in this category, was better than Africa. This suggests that significant improvements in telecommunication technologies, Internet and social media has diminished the distance and played an important role in social integration of people and countries.

The political globalization index in Figure 1.7 is based on the number of embassies in the country and the number of memberships in international organizations as well as the number of treaties signed between two or more countries - all suggesting a diffusion of government contacts and policies. As in economic and social globalization processes, political globalization gained a significant pace in the early 1990s and maintained it. Europe, Asia and Africa were the leaders of political globalization process.

As discussed earlier all globalization indicators have some weaknesses and there is no agreed upon threshold for globalization that will show whether it is reached. Therefore, it is not possible to conclusively say that the world is now fully globalized. However, the above discussed indicators show that the trend of integration progress has been upward for a long time and it is fairly clear that the world is no longer the same as in the 1980s and even 1990s. It has become much more integrated economically, socially and politically. 


\section{IMPACTS OF GLOBALIZATION ON NATIONAL, REGIONAL AND LOCAL ECONOMIES}

The first step in any globalization discussion is to review and understand the driving forces behind the integration process. What are the factors that made the integration possible? The second step is to understand how these factors convey the integration process to influenced countries. Finally, it is the analysis and understanding of the effects of the globalization and integration process on national and regional/local economies (Krieger-Boden and Soltwedel, 2013).

One of the major driving forces behind the globalization process is the technological advancement in production processes. This development widened the scope of industrial activities, increased the variety and quantity of goods produced and made it possible to ship these goods to far away locations. Improvements in information, communications and transportation technologies have expanded the gains from advanced production processes and have noticeably changed economic and social life around the world. Particularly, advances in mobile (cellular) phone technology, Internet and social media had a major role in this progress. These developments have reduced the distance and significantly increased the speed of economic and social transactions. This also altered the nature of services and increased the amount of knowledge-based producer services that are now easily traded across long distances (Cook and Kirkpatrick, 1997). It should be noted that the resulting economic and social integration stimulated further technological improvements.

Institutional and political developments are other factors that have shaped the globalization and integration process as much as technological advancements. Increased involvement of international organizations, particularly Bretton Woods institutions (International Monetary Fund, the World Bank Group), United Nations and related agencies, OECD and World Trade Organization (WTO), has been an important part of the globalization and integration process. These organizations guided and, to some degree, shaped the globalization process by establishing a common understanding among their member countries to benefit from enlarged markets (Dreher et al., 2008; Krieger-Boden and Soltwedel, 2013). As a result, many governments have adopted economic systems that are open to international trade and investments and negotiated international agreements to promote trade in goods, services and investment. Further, institutional progress may also foster integration by improving governance and providing a reliable and to some extent standardized basis for economic transactions.

Another important factor that contributed to the globalization and 
integration process and, to some degree, was affected by the progress itself, is innovations in industrial organizations and the expansion of multinational corporations. These corporations, through outsourcing and investing in different parts of the world, helped broaden the integration process, and their activities became central to the globalization (Cook and Kirkpatrick, 1997). In turn, their organizational and business structures have further evolved and changed.

These driving forces spread their influence on participating countries by reducing economic, social and political transaction costs, diminishing the importance of distances and making available new products, ideas and information. People around the world will get familiar with these new ideas, products and services, which will open up new markets for businesses and, in turn, boost further integration.

The dominant view about effects of globalization is that reduced transaction costs will increase trade of goods and services and improve international division of labor, which will lead to more efficient utilization of resources and economic growth (Cook and Kirkpatrick, 1997; Molle, 2002; Krieger-Boden and Soltwedel, 2013). It could be argued that globalization offers a major opportunity for improving welfare of developing countries. However, this will not be without conflict and some adjustment costs for all involved actors. The effects of globalization vary across nations and regions depending on the scope of opportunities opened up by the globalization and integration process as well as on the choices that the involved actors make to use these opportunities based on their preferences (Krieger-Boden and Soltwedel, 2013).

The effects of globalization have been uneven among nations and even among regions of a nation and benefits and costs associated with the process have differed noticeably. As seen in the earlier section most of the international trade and FDI took place among developed countries. Developing or newly industrialized countries of East and South East Asia have benefited more than Africa and South Asia. This is understandable given that capital tends to move toward more developed and industrializing countries where the return to investment is relatively high and less risky. Weak technological capacity and infrastructure and high degree of risk and uncertainty have been major constraints for developing countries to attract FDI. Further, weak administrative, institutional and organizational structures and capacity at the national level creates a big challenge to manage the globalization process (Cook and Kirkpatrick, 1997). The poorest countries do not benefit much from invention, innovation or the productivity effects of globalization. As a result, less developed countries and regions have limited opportunities to integrate into the world economy (Storper, 2009). This led to widening 
the gap between the less developed, poorer countries and developed countries.

The increased integration and a shift toward a higher share of international goods and services in national production and consumption will eventually require certain adjustments in production processes and resource allocation. Such adjustments are often associated with social costs and tension (Cook and Kirkpatrick, 1997). In most cases, inefficient domestic production processes cannot compete with relatively cheap and higher quality goods and services that could cause job losses in host countries. The skill set of released labor may not match the requirements of new export based jobs.

Globalization has also had some impact on developed counties. One of the main concerns was unemployment. Increased imports from relatively low-wage developing countries by high-wage developed countries could put pressure on the same sectors for plant closure or relocation, hence job losses. Even though some earlier studies found that this was not the case given the relatively small size of imports from developing countries (Molle, 2002), in some labor intensive and low-tech sectors this could be exactly the case. Such development will be in line with the product/regional life cycle theory (discussed in Chapter 5). Another concern for developed countries is that due to globalization demand for labor will shift toward a high-skilled and technology savvy labor, which will lead to a higher inequality in wage structures in developed countries. Particularly lowskilled, middle-aged workers will have hard time to find suitable jobs that will support their families if they become unemployed.

Another important outcome of the 'globalization revolution' particularly by the 'hyper-globalists' is the tendency to view the nation-state as a hindrance to the achievement of desirable economic and social outcomes (Rodrik, 2013). The underlying justification for this view is that the nationstate is the source of many transaction costs such as import tariffs, capital controls, visas, and other restrictions that impede the circulation of goods, money and people, and hence prevent further economic integration. Rodrik (2013) points out that for 'hyper-globalists' the more fundamental issue is that sovereign state creates jurisdictional discontinuities and associated transaction costs. Therefore, differences in currencies, legal regimes and regulatory practices are seen as the main obstacles to a unified global economy. Today, many nation-states are seen as overwhelmed by the driving forces of the globalization process. Many analysts argued that as part of the globalization process the balance of power in the economy is tilted in favor of multinational corporations at the expense of nations and regions. For example, decisions on many aspects of economic activities such as downsizing, closure and relocation of firms are taken by the 
multinational corporations in their remote headquarters and not by local entrepreneurs (Isaksen, 2001). This implies that global multinational corporations have the capacity to change the national and regional economies. Dicken (1994) even argued that some nation-states lost their bargaining power to international organizations and multinational corporations.

As will be discussed in the following chapters of the book globalization and economic development has a major local dimension. Communities around the world have different needs and preferences in terms of goods, services and institutional forms. Geography and distance are still key factors limiting the convergence in these needs and preferences. Markets in these regions and localities will need non-market institutions that will create, regulate, stabilize and legitimize these markets. These functions could be provided mainly by nation-states (Rodrik, 2013), and in some cases local government and local institutions play an important role.

It would be a fundamental mistake to detach globalization from national, regional and local economic development and to see it as simply spreading out of economy activity, or the transformation of the economic order across the world. In fact, globalization has been closely associated with the agglomerative tendencies in many different parts of the world due to the very openness and competitiveness that agglomeration convenes (Scott and Storper, 2003). In fact, globalization has made regional and local economies and their interaction more important for economic growth and prosperity. On the one hand, space has become slippery because capital, goods, people and ideas can now travel more easily. On the other hand, it is quite sticky and thick because capital, goods, people and ideas, tend to remain closer to large agglomerations. As a result, globalization has made local and regional economies more important due to the local nature of social, institutional and economic activities (Barca et al., 2012). It is, therefore, necessary to take the locational interdependencies into account to understand the role of cities and regions in formation of efficiency and innovation enhancing clusters as part of the development process. This is another indicator that the nation-state and local institutions should be seen as enablers of the integration and globalization process.

It is now obvious that the process of economic integration of countries at the global level has a local dimension. Regionalization is now seen as an important attribute of the globalization trend. During the last several decades, the growing number of regional clusters and innovation systems around the world and their strong positions in world markets for both traditional and high technology products is a good indicator of the role of regional economies in this trend (Isaksen, 2001). While regional and local economies of a country progressively integrate with each other, the country integrates with the rest of the world. The structural change, defined as the 
evolution of sectoral specialization at the country and regional levels, is a reflection of the joint dynamics of local and global integration (Imbs et al., 2012).

Due to globalization and liberalized international trade and hence reductions in transaction costs, distances and national boundaries have substantially diminished and most of the obstacles to access external markets have been removed. New technologies will now facilitate coordination and monitoring of economic activities and transactions that were previously done by intra-organizational hierarchies and external markets. This, to a large degree, played a role in the rise of living standards of people in many countries by improving the allocation of resources and by exerting discipline on economic policies through exposure to external competition.

This globalized competition has been forcing enterprises to develop new strategies to strengthen their competitive advantages within more unified markets, which, in turn, has triggered significant changes in the economic specialization of countries, regions and enterprises. Investment in new technologies, specialization in differentiated products and services, mergers and acquisitions and network organizations are some examples of these new strategies. Terms such as reengineering, restructuring, decentralization, flexible manufacturing, smart production, networked production, the virtual corporation and the information economy have become indicators of this new pattern (Haynes and Dinc, 2000). In the production process, the old vertically integrated large structures that were once necessary to coordinate complex transactions and to avoid delays in production were replaced by networked 'heterogeneous' production. As a result, production processes have become fragmented, where different pieces of the whole are now being produced in different regions and countries leading to a vast expansion in supply chains that are global. This is also true for a number of service sector activities.

As part of these developments the composition of intra- and interregional economic systems continues to show strong specialization while exhibiting significant interdependency, particularly on each other's basic infrastructure. In order to deliver inputs to production facilities and final products to consumers in a timely manner, the quality and effectiveness of infrastructure across trading regions has become a very important factor in decision-making process for new investments and for designing development programs. For example, congestion in Beijing could result in a delay in production in Istanbul, which could cause losing a new market in Germany to a competitor. While economic activities in different regions and countries have become increasingly interdependent, such closeness has brought increasing competition into the marketplace, which in turn has put additional pressure on local economies. In order to contend with 
this competition, local economies are obliged to harness a range of skills and resources to develop necessary infrastructure simultaneously. In this environment, competitiveness increasingly depends on the synergy generated by a broad range of specialized industrial, financial, technological, commercial, administrative and cultural skills sometimes even located in different regions and continents.

The reduction or elimination of trade barriers and liberalization of capital flows, combined with advances in communications technology and transportation have brought new opportunities to regional and local economies while simultaneously exposing them to increased competition from both domestic and foreign competitors in all markets and in a large number of areas. Within the context of an increasingly integrated world economy, regional and local economies have become more and more crucial for national economies and in some cases dominate national economies from a leading technology or entrepreneurial perspective. The outcome of this new trend has been the spatially decentralized but economically functional technological regions around the world (Haynes and Dinc, 2000).

The rise of local and regional economies as the building blocks of the new world economic landscape has been widely recognized by scholars across the world (Ohmae, 1993; Sabel, 1989; Porter, 1990; Krugman, 1991, 1995; Scott and Storper, 2003). Scott (2001) suggests that city regions have been functioning as the basic engines of the global economy, and, in fact, globalization and local-regional development are two facets of a single reality. Harrison (2007), in a sense, supports Scott and argues that while globalization removes or reduces the boundaries for some flows and processes, regionalization makes them rooted in a series of place-sensitive nodes of dense economic and social activity. Harrison also suggests that competition and cooperation among these dynamic regions will dictate the future more than will nation-states themselves.

Such regions are increasingly polycentric and they continue to expand toward lower residential densities where major factors of production are sufficient and more cost-effective. In support of such regions, communication and transportation technologies continue to enable lateral growth across the regional periphery rather than in the traditional hierarchical mono-centric radial fashion of the past. Manufacturing, for example, continues to decentralize toward cost-effective regions with the help of information technologies as well as improved transportation infrastructure. New manufacturing methods, including flexible manufacturing, just in time production, niche specific production and customer focused production are, in a sense, part of the expansion and decentralization process. This can be seen as a response to intensified competition due to globalization in most sectors. In order to take advantage of these new 
production technologies effective and rapid responses are required in the production chain, all the way from suppliers to customers. This means that hard infrastructure, telecommunications and information infrastructure become one of the central foundations of the production and high-end services processes.

It should be kept in mind that the globalization process could provide significant benefits for developing countries if the process is managed effectively at the national and international level to minimize the adjustment costs. At present, in many countries around the world, institutional set-up is not in a position to effectively deal with the fast changing economic and social environment and its problems let alone transform them into opportunities (Cook and Kirkpatrick, 1997). Since the 1980s, policies took an influential shift in favor of markets and against governments. The result was nationally smaller governments and internationally a push for what Rodrik (2013) called hyper-globalization. This process significantly weakened the domestic governance structures and at the same time, their global counterparts remained incomplete. Pushing policy/rule making onto supranational domains too far created a situation that was beyond the reach of political debate and control.

As Rodrik (2013) fittingly pointed out, combining globalization with healthy domestic institutions and policies could manage this tension quite well. Moving too much in the direction of globalization would deteriorate the domestic institutions that are necessary for markets. Moving too much in the direction of the state and protectionism would cause losing significant benefits from international trade and globalization. Evidence shows that the countries that performed the best in the new regime were those that found the right balance of both worlds. He proposes a simple principle that could bring both opponents and proponents of globalization together if they accept it: countries can uphold national standards in labor markets, finance, taxation, and other areas and can do so by raising barriers at the border, if necessary, when international trade and finance demonstrably threaten domestic practices that enjoy democratic support (Rodrik, 2013, p. 17, original emphasis).

One should not forget that globalization is just a tool for societies around the world to attain prosperity, stability, freedom and quality of life in their countries, regions and communities, not a goal itself.

Two topics have emerged out of the above discussed developments as the dominant economic development characteristics of the post-Cold War period: globalization and regionalization/localization. Globalization and regionalization/localization process may seem like conflicting concepts, but they are really complementary when examined in an integrated framework.

One very important implication of increasingly interdependent economic 
activities among different regions and countries is the increased and more intense competition in the marketplace, which, in turn, has put additional pressure on the regional and local economies. In such a globalizing and increasingly borderless economic environment, understanding local and regional economies and the driving forces behind them as well as relevant theories and approaches that explain such developments is vital.

\section{THE NEED FOR LOCAL AND REGIONAL ECONOMIC ANALYSIS}

It is a well-known fact that across the world regional and local economies have different economic, social and natural endowments. Some regions have had favorable initial conditions in the form of rich natural resources or close proximity to major markets and trading partners. Some others had to create them over time in the form of good infrastructure, a well trained workforce, local entrepreneurship capacity, effective local leadership with well-designed development policies, local research facilities, and an enabling business environment that could compensate for the initial disadvantages. Still, in many countries, a large number of regional and local economies neither had favorable initial conditions nor were able to create them on their own; and hence were left behind where declining local industries and low rates of new business formation became endemic. Obviously these factors create an adverse environment for the growth and development, and hence trigger a vicious cycle of decline (Stough, 2014).

As Tomaney (2010) argued local and regional economic development processes need to meet global challenges that require locally developed responses. In this changing and globalizing economic environment, if local and regional economies cannot develop and adopt new ways to deal with these problems, they will not be able to keep pace in this fast moving world.

Many countries have developed numerous regional development programs and established local and regional development agencies to address the uneven development issue. Given that we are now living in a globalized and continually changing environment, it is more likely that uneven economic, social and cultural development of regions will remain a common incidence. The increasing importance of regional and local economies as the building blocks of the new world economy makes addressing local and regional development more critical than ever. Hence, it is quite reasonable to assume that policymakers at all levels will devote a significant amount of time and energy to address local and regional development related issues in coming years. In the process, some new approaches will emerge while some 
of the existing ones will be revised and reformulated to accommodate the new environment within which local and regional economies operate.

The OECD (2009) reports that regional policies in most of its member countries started in the 1950s and 1960s when countries were benefiting from a period of relatively strong economic growth, fiscal expansion and low unemployment. With the availability of new sub-national level statistics, all of a sudden, regional inequality became more visible. Hence, many countries introduced policies with an objective of greater equity and balanced regional growth and development. However, these policies have, to a large degree, relied on the 1950s growth and development theories and mainly been supply-side strategies focusing on a sectoral rather than a regional dimension. They did not pay attention to the specifics of the wider regional and local context. In these policies, decision-making was mainly top down, and relied on state aid, financial support, incentives and subsidies as key elements of the strategy. As a result, the same solutions have been applied to similar problems in different places without much success (Barca et al., 2012).

The major instruments employed during this period were mainly public financed large investment and infrastructure projects as well as wealth redistribution through financial transfers by the national government. These policies were relatively simple to design and results (such as roads and other large scale infrastructure investments) are visible and hence quite attractive for policymakers. In a global and increasingly diverse economic world, these supply-side, top-down policies have not been able to handle the new reality and could not produce desired results and eventually deepened uneven development.

Successive economic crises of the 1970s and early 1980s, and emerging changes in the world economy forced many countries to shift their focus from reducing regional disparities to more job creation. This new approach was based on the assumption that it is possible to reduce the cost of major production factors by public interventions in the form of subsidies and incentives that would, in turn, influence the location decisions of firms and attract new investments (OECD, 2009).

These nationally developed policies, however, have not produced the anticipated results; and a general consensus has emerged that in a market economy and in a globalizing world the role of national governments in changing the basic spatial patterns of the national economy is very limited (Polèse, 1999). As a result, around the world local and national governments started moving away from these policies that focused on large scale public investments, transfer payments to local economies and the attraction of footloose industries and investors. Instead, the focus shifted toward the identification and mobilization of the endogenous potential of the 
region or locality to rely on its own resources to grow. This new approach also emphasizes the full utilization of economic potential of the region that is unused or underutilized and not easily identifiable to outside actors (Tomaney, 2010).

The main principle of the new local and regional development approaches is that the successful development of a region will depend heavily on the capacity of local players (firms, individuals, policymakers, etc.). If they can take matters into their hands and organize all stakeholders around a common goal to adapt and adjust to outside changes, then sustainable regional development will be possible. It is a fair statement that the ultimate source of development is within the region, in its people, its institutions, its sense of community, and, perhaps most important of all, in the spirit of innovation and entrepreneurship of its population (Polèse, 1999).

It was observed that regional development policies have significantly evolved from the old top-down, subsidy based interventions primarily designed for reducing regional inequalities to the new much broader bottom-up policies that are designed to improve the competitiveness of the region (OECD, 2009). These new policies are structured around four major pillars: a multi-year comprehensive development strategy that covers all relevant factors that affect the performance of local firms; a focus on local assets, rather than relying on external investments and transfers; an emphasis on identifying and utilizing opportunities for growth and development, rather than restoring the consequences of decline; and the prominence of an agreed upon multi-level governance structure with a stronger role for local and regional actors, including business and other social partners, in the formulation of development policies (OECD, 2009; Tomaney, 2010). The surge in the use of the Regional Development Agency model around the world may be viewed as a step forward to establishing good local and regional governance structure for sustainable economic development.

The environment within which regional economies operate has undergone a series of evolutionary changes in the recent past that shaped the way regional and local communities think and plan for their future. In this environment, exogenous factors or shocks (such as exchange rates, new technologies and foreign competition) have a significant impact on the decision-making processes of regions. It was observed that many regions are not re-equipping themselves fast enough to compete effectively in the global age of business and technology of the post-industrial knowledge economy (Stimson et al., 2006). To avoid the negative effects of globalization and benefit from the process regional organizations and businesses need to understand the implications of the paradigm shifts occurring in economic policy and strategy. 
It is more likely that there will be further changes in the economy due to globalization whether it is associated with the expansion or the decline of economic activities. In most cases, it is not easy to identify the reason behind these changes, and managing the consequences of these changes and taking corrective action is often difficult. Further, such changes in the economy put significant fiscal pressure on governments at the central and local levels due to continuing demands for public services. Generally, the major revenue sources for these governments are not able to keep up with the rising demands; and resources usually are available only with a certain time lag. The same is also true for declining regions; the demand for public services does not fall at the same rate with population decline resulting from a worsening economy.

Any change in the economy has an impact on all agents, small or large. Therefore, as suggested by Hoover and Giarratani (1999), all stakeholders (policymakers, firms, research institutions, international organizations, the general public etc.) are concerned with the following key questions:

- Causes of growth or decline. Why do some regions grow (decline) faster than others? What are the primary factors responsible? What is the role of interregional trade, migration and investment in the development level of different regions?

- Structure of the local and regional economy. What is the relationship between economic structure of the region and growth? What is the best sectoral mix that is conducive to growth?

- Convergence or divergence. Are the regions converging or diverging? Is convergence (divergence) common and inevitable, or is it subject to reversals?

- Control over development and growth. Is it possible to guide development and growth by policy? What are the objectives and appropriate policies?

- Governance, institutions and local leadership. Does the region/ locality have a good governance structure with leadership and necessary institutions?

The above questions are only one part of the development equation. A number of other factors are discussed in the following sections that will complete the equation. These factors will help determine the location decisions of firms and consumers and hence the development of local economies, to which decision-makers at all levels need to pay close attention. These factors can change over time as a result of improvement in information, communications and transportation technologies and improved local and regional institutions and physical infrastructure. It is 
more likely that globalization, as discussed earlier, will have an impact on these changing factors.

In analysing regional economic development it is necessary to understand overall progress in the regional/local economy and society as a whole resulting from globalization and other changes. These may affect local and regional economies differently, while historical, social and cultural characteristics of the region/locality will inspire learning and the creation of region-specific competencies differently. This suggests that the quality of localized social interaction and learning should be supported by non-local linkages through incorporation of new ideas and knowledge into placespecific learning and innovation processes that are essential in sustaining competitiveness (Isaksen, 2001).

Local, regional and national political and social institutions are the key for shaping the business climate within which all actors of the economy operate. The business climate is affected by major cost factors such as land, labor, capital, taxes and regulations as well as non-cost factors such as infrastructure, quality of life, local and regional amenities, and attitudes toward business where inclusive political institutions play a determining role (Acemoglu and Robinson, 2012). In almost every country, both national and local governments have a big impact on business climate by providing various services, regulation and improving local amenities that eventually influence local economic development.

In today's global economy, firms have greater mobility and a broader range of alternatives for their location decisions than ever. Given that the private sector has been driving economic growth and development in a market economy, creating a business climate in which agents of society can interact efficiently and effectively becomes crucial. Such an environment will help countries and regions retain and expand existing businesses and attract new investments, all of which will help generate new jobs and income. New investment decisions by both domestic and foreign firms entail a lengthy process, and in most cases involve considerable research, particularly in terms of where these new investments will be located.

Governments at all levels have a big role and responsibility in creating a business environment that is conducive to growth and development. For example, the availability and accessibility of information will shorten the decision-making process and reduce its costs significantly, and the resulting evidence-based investment decisions will be much more accurate (Dinc, 2003). Further, in order to properly monitor the development progress, particularly at the regional and local level, having access to relevant, reliable information on a timely basis along with the necessary analytical tools is essential. The information provision is one example that could be provided by relevant government agencies. Of course, policymakers at all 
levels of government also need such information to develop proper programs and to monitor the results and outcomes of these programs as part of their role as supporters, regulators and supervisors. It should be kept in mind that some of the responsibilities that could affect the business climate could be beyond local government control such as taxes, rules and regulations that govern establishing and operationalizing business.

While monitoring the globalization and its impact on the local and regional economy, local policymakers need to develop their own programs to benefit from globalization. To develop and support sound policies it is necessary to understand the industrial structure of the nation and its regions, that is, which sectors are the leading sectors in terms of volume of activity, value added or share of labor demand, and which ones are growing or declining regionally and nationally. More importantly, it is also necessary to appreciate how industrial sectors of the region are performing relative to other regions in terms of efficiency and productivity because productivity growth is one of the most important sources of competitiveness in an interactive world economy.

Further, policymakers also need to understand how much a given industry, firm, regional economy or the nation can increase its output without absorbing additional resources, thereby improving its efficiency and competitive status. In that sense, efficiency becomes an important control parameter for assessing the utilization level of inputs in the production process. Just as the viability of firms in a long-term competitive environment depends heavily on their efficiency, the overall efficiency or productivity of the economy of countries, regions or localities determines the general well-being of their people (Rivlin, 1992).

Therefore, understanding, measuring and explaining productivity growth and its impact on a regional economy is very important and should be a main concern of regional policymakers. Any economic development policy, in one way or another, will have an impact on allocation and/or reallocation of resources. For example, in the short run an industrial sector in a region may be 'leading' in terms of volume of activity, value added or share of labor demand, but if it is not operating efficiently compared with the same sector in other regions sooner or later it will become uncompetitive and begin to wither away from external competition. Alternatively, a less dominant sector may be a better candidate for growth and development because of its competitive efficiency.

Due to the changing role of regional and local economies as building blocks of the national economies and the impacts of globalization as well as the new concerns about sustainable development, policymakers need to take some new factors into account in formulating economic development strategies (Stimson et al., 2006). Given that each region has its own unique 
characteristics and factors, there is no one-fits-all model or framework for regional economic development. Stimson et al., (2006) suggest that the intent of a regional economic development strategy should be to establish a platform for change that could provide guidance for regional economic development and facilitate its competitiveness in a global environment in the pursuit of a sustainable future. Further, it should target mobilizing key actors and agents of change through strategic alliances and partnerships between business, markets, government and the community.

As fittingly stated by Polèse (1999) local policymakers need the hard knowledge of local conditions, technical competence, sound judgment, and a realistic understanding of the forces that shape the economic geography of regions that requires solid local and regional economic analysis.

\section{NOTE}

1. See for more information http://globalization.kof.ethz.ch/ (accessed July 13, 2015). 